\title{
EAF2 loss enhances angiogenic effects of Von Hippel-Lindau heterozygosity on the murine liver and prostate
}

\author{
Laura E. Pascal · Junkui Ai • Lora H. Rigatti • \\ Anne K. Lipton • Wuhan Xiao · James R. Gnarra • \\ Zhou Wang
}

Received: 28 March 2011/Accepted: 10 May 2011/Published online: 3 June 2011

(C) The Author(s) 2011. This article is published with open access at Springerlink.com

\begin{abstract}
Von Hippel-Lindau (VHL) disease results from the inactivation of the VHL gene and is characterized by highly vascular tumors. A consequence of VHL loss is the stabilization of hypoxia-inducible factor (HIF) alpha subunits and increased expression of HIF target genes, which include pro-angiogenic growth factors such as vascular endothelial growth factor (VEGF). In mice, homozygous deletion of VHL is embryonic lethal due to vascular abnormalities in the placenta; and, $\mathrm{VHL}^{+/-}$mice develop proliferative vascular lesions in several major organs, most prominently the liver. Loss of ELL-associated factor (EAF2) in murine models has also been shown to induce increased vascular density in the liver as well as the prostate. Previously, EAF2 was determined to be a binding partner of VHL and loss of EAF2 induced a reduction in pVHL levels and an increase in hypoxia induced factor $1 \alpha$
\end{abstract}

Electronic supplementary material The online version of this article (doi:10.1007/s10456-011-9217-1) contains supplementary material, which is available to authorized users.

L. E. Pascal · J. Ai · A. K. Lipton - W. Xiao ·

J. R. Gnarra $\cdot$ Z. Wang $(\bowtie)$

Department of Urology, University of Pittsburgh School of

Medicine, Suite G40, 5200 Centre Avenue, Pittsburgh,

PA 15232, USA

e-mail: wangz2@upmc.edu

L. E. Pascal

e-mail: pascalle@upmc.edu

J. Ai

e-mail: aij@upmc.edu

A. K. Lipton

e-mail: liptonak@upmc.edu

W. Xiao

e-mail:w-xiao@ihb.ac.cn

J. R. Gnarra

e-mail: gnarrajr@upmc.edu
$(\mathrm{HIF} 1 \alpha)$ levels in vitro. Here we characterized the cooperative effects of VHL- and EAF2-deficiency on angiogenesis in the liver and prostate of male mice. VHL deficiency consistently increased the incidence of hepatic vascular lesions across three mouse strains. These vascular lesions where characterized by an increase in microvessel density, and staining intensity of VHL target proteins HIF $1 \alpha$ and VEGF. EAF $2^{-1-} \mathrm{VHL}^{+-}$mice had increased incidence of proliferative hepatic vascular lesions (4/4) compared to $\mathrm{VHL}^{+/-}(10 / 18)$ and $\mathrm{EAF}^{-/-}(0 / 5)$ mice. Prostates of $\mathrm{EAF}^{-1-} \mathrm{VHL}^{+/-}$mice also displayed an increase in microvessel density, as well as stromal inflammation and prostatic intraepithelial neoplasia. These results suggest that cooperation of VHL and EAF2 may be critical for angiogenic regulation of the liver and prostate, and concurrent loss of these two tumor suppressors may result in a pro-angiogenic phenotype.

\author{
L. H. Rigatti \\ Division of Laboratory Animal Resources, University of \\ Pittsburgh Cancer Institute, University of Pittsburgh, Pittsburgh, \\ PA 15261, USA \\ e-mail: rigattil@pitt.edu \\ W. Xiao \\ Institute of Hydrobiology, Chinese Academy of Sciences, \\ Wuhan 430072, People's Republic of China \\ A. K. Lipton $\cdot$ Z. Wang \\ Department of Pharmacology and Chemical Biology, University \\ of Pittsburgh School of Medicine, Pittsburgh, PA, USA
}


Keywords Von Hippel-Lindau (VHL) · ELL-associated factor 2 (EAF2) - Hepatic vascular lesion · Prostatic intraepithelial neoplasia (PIN)

\section{Introduction}

Von-Hippel-Lindau (VHL) gene inactivation results in a cancer syndrome characterized by tumors at various sites, including vascular tumors of the retinas and central nervous system, renal cancers, adrenal pheochromocytomas, and pancreatic tumors. The VHL protein (pVHL) is an E3 ubiquitin ligase that regulates hypoxia inducible factors alpha subunits (HIF $1 \alpha$ and HIF2 $\alpha$ ) through targeted ubiquitination and proteasomal degradation under normoxic conditions [1-3]. Under hypoxic conditions pVHL levels are decreased [4] and HIF $\alpha$ subunits accumulate. The activated HIF transcriptional response results in expression of hundreds of genes whose products are involved in metabolism, cellular proliferation, and angiogenesis [5]. Although conventional deletion of VHL is embryonic lethal in the mouse due to placental vascular defects [6], conditional VHL deletions have been shown to induce hepatic vascular lesions [7-10], renal cysts [11] and pancreatic lesions [12].

Previously, we have shown that the androgen-responsive tumor suppressor ELL-associated factor 2 (EAF2) could block HIF-dependent angiogenesis by binding and stabilizing pVHL [13]. EAF2 ${ }^{-1-}$ mice had reduced levels of pVHL in the testes; and mouse embryonic fibroblasts derived from $\mathrm{EAF}^{-1-}$ mice had an increased activity and level of HIF1 $\alpha$ [13]. Furthermore, EAF2 $2^{-1-}$ mice displayed an increase in blood vessel formation in the liver at 3 months of age [14]. These studies suggest that EAF2 may cooperate with VHL in the regulation of blood vessel formation and growth, and concurrent loss of function of VHL and EAF2 could contribute to a pro-angiogenic phenotype.

In order to further characterize the role of EAF2 and VHL in angiogenesis, we examined the effects of EAF2 loss and VHL heterozygosity in murine prostate and liver. Here we report that EAF2 ${ }^{-/-} \mathrm{VHL}^{+/-}$mice had an increased incidence in hepatic vascular lesions as well as increased liver and prostate vascularity compared to wild-type, $\mathrm{EAF}^{-/-}$and $\mathrm{VHL}^{+/-}$mice. Increased vascularity in the liver was characterized by an increase in HIF $1 \alpha$ and VEGF immunoreactivity, particularly in hepatocytes near vascular lesions. In the prostates of $\mathrm{EAF} 2^{-l-} \mathrm{VHL}^{+1-}$ mice there was an increased incidence of PIN, stromal inflammation, fibrosis and smooth muscle proliferation compared to wild-type, $\mathrm{EAF}^{-1-}$ and $\mathrm{VHL}^{+/-}$mice.

\section{Materials and methods}

Generation of strain-specific VHL deletion mice

$\mathrm{VHL}^{+/-}$mice [6] were generated by backcrossing to the $\mathrm{BALB} / \mathrm{c}, \mathrm{FVB} / \mathrm{N}$ and $\mathrm{C} 57 \mathrm{BL} / 6 \mathrm{~J}$ strains (NCI Animal Production Facility, Frederick, MD, USA) for $>12$ generations to generate $\mathrm{VHL}^{+/-}$mice with a pure background. Wild-type and $\mathrm{VHL}^{+/-}$mice were maintained identically, under approval by the Institutional Animal Care and Use Committee of the Louisiana State University Health Sciences Center, New Orleans. Genotyping was determined by PCR analysis of mouse tail genomic DNA as described previously [6]. Mice were sacrificed at 12-15 mos of age.

Generation of EAF2 and VHL deletion mice on a $\mathrm{C} 57 \mathrm{~B} 1 / 6$ background

Preparation of mice with specific deletion of EAF2 gene using HM1 embryonic stem cells has been described previously $[14,15] . \mathrm{EAF}^{+/-}$mice were subsequently backcrossed to the C57BL/6 J strain (Jackson Laboratory, Bar Harbor, ME, USA) for $>12$ generations to generate $\mathrm{EAF}^{-1-}$ mice with a pure $\mathrm{C} 57 \mathrm{BL} / 6 \mathrm{~J}$ background. $\mathrm{EAF}^{-1-} \mathrm{VHL}^{+/-}$mice were generated from heterozygous intercrosses of $\mathrm{EAF}^{+/-}$and $\mathrm{VHL}^{+/-}$mice (obtained from Dr. Laura Schmidt [8]) and subsequently from homozygous EAF2 ${ }^{-/-} \mathrm{VHL}^{+/-}$intercrosses. Experimental cohorts were wild type, $\mathrm{EAF}^{-/-}, \mathrm{VHL}^{+/-}$, and $\mathrm{EAF}^{-/-} \mathrm{VHL}^{+/-}$ male littermates. All mice were on a C57BL/6 background and were maintained identically, under approval by the Institutional Animal Care and Use Committee of the University of Pittsburgh. Genotyping was determined by PCR analysis of mouse tail genomic DNA as described previously [15]. Mice were sacrificed at $12-15$ mos and 20-24 mos of age. Organs were cleaned of excess fat and membrane with phosphate-buffered saline and mass was determined by weighing after blotting with filtration paper to remove excess liquid. Prostate mass was determined as absolute mass as well as a ratio of organ to body mass to correct for body weight differences as described [16]. Samples were fixed in $10 \%$ formalin for at least $24 \mathrm{~h}$, then embedded in paraffin, sectioned at $5 \mu \mathrm{m}$, and stained with hematoxylin and eosin.

Immunohistochemistry

Immunohistochemical stains were performed on fivemicron sections of paraffin blocks. Briefly, the sections of all groups were deparaffinized and rehydrated through a graded series of ethanol. Heat induced epitope retrieval was performed using $10 \mathrm{mmol} / \mathrm{L}$ of citrate buffer $(\mathrm{pH} 6)$, followed by rinsing in TBS buffer for $5 \mathrm{~min}$. The primary 
antibodies (working dilution 1:400) were rat monoclonal anti-CD31 (MEC 13.3, 550274, BD Biosciences, San Jose, CA, USA), Ki-67 (TEC-3, M7249, Dako, Carpinteria, CA, USA), VHL (Ig32, 556347, BD Biosciences), HIF1 $\alpha$ (54, 610959, BD Biosciences), VEGF (P-20, sc-1836, Santa Cruz Biotechnology, Santa Cruz, CA, USA). Slides were then counterstained in hematoxylin and cover-slipped. Sections were imaged using a Zeiss Axioplan2 microscope and Axiovision Rel. 4.5 imaging software. Composite images were constructed with Photoshop CS (Adobe Systems, San Jose, CA). Extent of immunostaining was determined according to the presence or absence of specific staining when compared to positive and negative controls (Supplemental Figure 1). CD31-positive vessel density and Ki-67-positive cell density were determined by analysis of sections from at least 4 independent mice from each genotype. Assessment of microvessel density was determined based on CD31-positive blood vessel count as previously described [14]; proliferative index was determined based on cell count as described [10]. Briefly, microvessel density was determined from at least 20 fields imaged at $10 \times$ magnification for prostate and $40 \times$ magnification for liver with no overlap and identified by evaluating histological sections, and CD31-positive vessels were counted to determine the average vessel numbers per field for each section. Proliferative index was determined from at least 20 fields imaged at $40 \times$ magnification with no overlap, Ki-67positive cells were counted to determine the average number of proliferating cells for each section. All tissues were examined by an animal pathologist (L. Rigatti).

\section{Cell culture and transfection}

Primary mouse embryonic fibroblasts (MEF) were generated from embryonic day 12.5 (E12.5) to day 13.5 (E13.5) mixed C57BL/6 J/129 background embryos [13]. MEFs were maintained in DMEM with $10 \%$ fetal bovine serum (FBS), $0.1 \mathrm{mmol} / \mathrm{L}$ nonessential amino acids (Invitrogen), $100 \mu \mathrm{mol} / \mathrm{L}$ 2-mercaptoethanol (Sigma), and penicillin/ streptomycin. MEFs were transfected using Lipofectamine 2000 (Invitrogen) in OPTI-MEM (Invitrogen). GFP-positive cells were sorted using flow cytometry. GFP-positive MEFs were then cultured in DMEM with $250 \mu \mathrm{m} \mathrm{CoCl}_{2}$ to simulate hypoxia for $4 \mathrm{~h}$, and cell lysates were collected for Western blot analysis. To control for variation, transfection experiments were repeated using several different clones.

\section{Plasmids}

The full length human EAF2 cDNA was subcloned into pEGFP-C1 vector (Clontech, Mountain View, CA, USA) to generate pEGFP-EAF2. In-frame cloning of the pEGFPEAF2 fusion was verified by sequencing.
Western blot

Proteins were lysed in RIPA lysis buffer $(50 \mathrm{mM}$ Tris $\mathrm{HCl}$ pH7.4, 1\% NP-40, $0.25 \%$ sodium-deoxycholate, $150 \mathrm{mM}$ NaCl. $1 \mathrm{mM}$ EDTA pH 8.0, $1 \mathrm{mM} \mathrm{NaF}$ ) supplemented with $1 \mathrm{mM}$ PMSF, $1 \mathrm{mM} \mathrm{NaV} \mathrm{O}_{4}$, and $1 \times$ protease inhibitor cocktail (P8340, Sigma-Aldrich, St Louis, MO, USA). Frozen livers were homogenized, and cells were placed on ice for $30 \mathrm{~min}$ and then centrifuged at $13,000 \mathrm{~g}$ for $10 \mathrm{~min}$ at $4^{\circ} \mathrm{C}$. Protein concentration was determined by BCA Protein Assay (Thermo Scientific, Rockford, IL, USA). Proteins (50 $\mu \mathrm{g}$ ) from livers or whole cell MEF lysates were denatured and separated on a $10 \%$ SDS-polyacrylamide gel and transferred onto a nitrocellulose membrane. Blotted proteins were probed with antibodies as follows: mouse monoclonal anti-HIF $1 \alpha$ antibody (1:2,000, 610958, BD Transduction Laboratories), rabbit polyclonal HIF1 $\alpha$ (1:500, NB-100-449, Novus Biologicals, Littleton, CO, USA), rabbit polyclonal GFP (1:5,000, TP401, Torrey Pines Biolabs, Houston, TX, USA), rabbit polyclonal GAPDH (1:1,000, FL-335, sc-25778, Santa Cruz Biotechnology) and goat polyclonal $\beta$-actin $(1: 1,000$, C-11, sc-1615, Santa Cruz Biotechnology), followed by horseradish peroxidase-conjugated secondary antibodies (Santa Cruz Biotechnology). Signals were visualized by enhanced chemiluminescence (ECL Western Blotting Detection Reagents, GE Healthcare) and were exposed to X-ray film (Fuji film, Valhalla, NY, USA). Membranes were stripped between antibody probes using a stripping solution ( $\beta$-ME, 10\% SDS, $0.375 \mathrm{M}$ Tris $\mathrm{pH} 6.8$ ).

Computational analysis of gene expression datasets from human prostate tissue specimens

Previously published datasets were queried for differential expression of CD31, EAF2 and VHL pathway genes VHL, HIF1A, HIF1AN (HIF1A inhibitor), VEGFA, VEGFB, and VEGFC in human prostate tissue specimens. Cell-type specific transcriptome profiles from normal prostate $\mathrm{CD}^{2} 6^{+}$luminal epithelial and $\mathrm{CD}^{+} 9^{+}$stromal cells [17] were compared to $\mathrm{CD}_{2} 6^{+}$cancer $[18]$ and $\mathrm{CD}^{+} 0^{+}$cancerassociated fibroblasts [19]. The data were reported as robust multi-array average (RMA) [20] normalized Affymetrix signal intensities implemented in an in-house analysis pipeline SBEAMS [21], or as a composite value: $\mathrm{X}=\log _{2}$ (Cancer normalized intensity;Normal normalized intensity).

Statistical analysis

Comparison between groups was calculated using the twotailed Fisher's exact test method of summing small $P$ values and the 1-way ANOVA and Bonferonni's Multiple 
Comparison Test as appropriate. The level of significance was set at $P=0.05$. GraphPad Prism version 4 was used for graphics (GraphPad Software, San Diego, CA, USA). Values are expressed as means \pm SEM.

\section{Results}

VHL heterozygosity promotes the development of hepatic vascular lesions in a panel of murine strains

Mouse models from different genetic backgrounds often display variable phenotypes. We examined the incidence of vascular lesions in the liver induced by VHL heterozygosity in 3 inbred mouse strains: BALB/c, FVB/N and C57BL/6 at age 12-15 mos. Incidence of hepatic vascular lesions ranged from $33.3 \%$ in $\mathrm{VHL}^{+/-} \mathrm{FVB} / \mathrm{N}$ to $87.5 \%$ in $\mathrm{VHL}^{+/-}$BALB/c mice (Fig. 1). Although there was variability in incidence across strains, no hepatic vascular lesions were detected in any of the wild-type mice examined, regardless of strain $(P<0.05)$. Therefore, in agreement with earlier studies [7-9], heterozygous pVHL inactivation is significantly associated with the development of hepatic vascular lesions.

EAF2 and VHL-deficiency cooperate to promote hepatic vascular lesions in C57BL/6 mice

To examine the potential cooperative effects of EAF2 and VHL in the development of hepatic vascular lesions, $\mathrm{EAF}^{-1-} \mathrm{VHL}^{+/-}$mice on a $\mathrm{C} 57 \mathrm{BL} / 6$ background were generated and compared to wild-type, $\mathrm{EAF}^{-1-}$ and $\mathrm{VHL}^{+/-}$mice. At ages 20-24 mos, all mice were sacrificed and organs were harvested, paraffin-embedded and sectioned for histological analysis. Histological analysis revealed several defects in the liver of $\mathrm{VHL}^{+/-}$and $\mathrm{EAF}^{-1-} \mathrm{VHL}^{+/-}$mice and prostates of $\mathrm{EAF}^{-1-}$ and

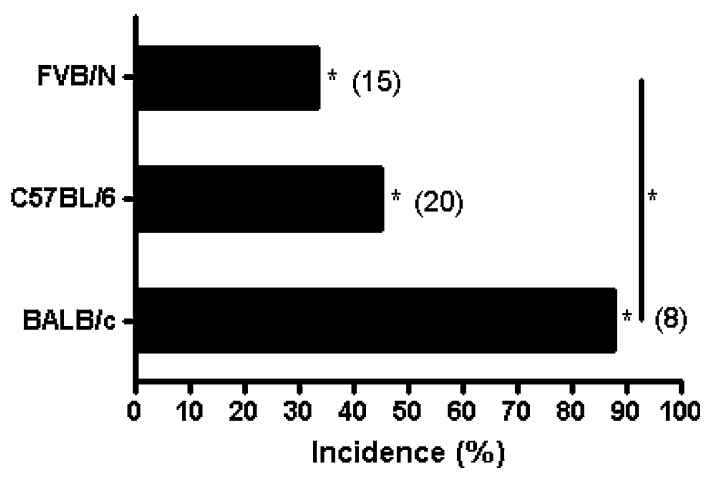

Fig. 1 Strain-specific incidence rate of hepatic vascular lesions in $\mathrm{VHL}^{+/-}$mice at ages $12-15$ mos. No hepatic vascular lesions were found in any wild-type control mice from each strain $(* P<0.05)$
EAF2 ${ }^{-/-} \mathrm{VHL}^{+/-}$mice (Table 1). The livers of wild-type and $\mathrm{EAF} 2^{-1-}$ mice displayed no visible abnormalities at age $20-24$ mos. However, 10 out of $18(55.6 \%) \mathrm{VHL}^{+/-}$ and 4 out of $4(100 \%) \mathrm{EAF}^{-/-} \mathrm{VHL}^{+/-}$mice displayed large discrete lesions visible both on the surface of the liver and within the liver parenchyma (Fig. 2a). Histological analyses confirmed moderate to severe angiectasis in the $\mathrm{VHL}^{+/-}(10 / 18)$ and increased incidence of hepatic lesions in $\mathrm{EAF}^{-1-} \mathrm{VHL}^{+/-}(4 / 4, P=0.25)$ mice (Fig. 2b). $\mathrm{EAF}^{-/-} \mathrm{VHL}^{+/-}$mice also displayed increased focal thrombus formation, mild focal lymphocytic infiltration, hepatocyte loss, hepatic fibrosis and hepatocellular adenoma (Table 1).

\section{Effects of EAF2 and VHL loss on prostate}

Mice in all groups had similar body mass (Fig. 3a). Grossly, the prostates of all mice displayed no visible abnormalities at age 20-24 mos. Although not significant, there was an increase in prostate mass associated with EAF2-deficiency in line with previous reports (Fig. 3B, C) [15]. Histological analysis revealed several defects in the prostates of $\mathrm{EAF}^{-/-}$and $\mathrm{EAF} 2^{-1-} \mathrm{VHL}^{+/-}$mice (Table 1, Fig. 3d, e). Compared to wild-type, EAF2 ${ }^{-1-}$ mice displayed an increased incidence of prostatic intraepithelial neoplasia (PIN) (3/5), stromal fibrosis and fibroplasia and stromal edema. $\mathrm{VHL}^{+/-}$mice displayed increased stromal inflammation, fibrosis and fibroplasia, but not PIN. One $\mathrm{VHL}^{+/-}$mouse displayed lymphoma in the prostate. $\mathrm{EAF}^{-/-} \mathrm{VHL}^{+/-}$mice displayed increased incidence of PIN (4/4), stromal inflammation (4/4), and stromal fibrosis and fibroplasia (4/4) (Fig. 3d, e). Mild multifocal lymphocytic interstitial infiltrates were observed in all mice in all groups, possibly due to aging.

EAF2- and VHL-deficiency affects cellular proliferation in the murine prostate and liver

The proliferative marker Ki-67 was used to detect dividing cells in the prostate and liver of each genotype. In the prostate, the number of Ki-67-positive epithelial cells was significantly increased in $\mathrm{EAF}^{-/-}$and $\mathrm{EAF}^{-/-} \mathrm{VHL}^{+/-}$mice as compared to wild-type or $\mathrm{VHL}^{+/-}$mice (Fig. 4a, c). Since the number of Ki-67-positive cells was not significantly different between wild-type and $\mathrm{VHL}^{+/-}$or between $\mathrm{EAF}^{-/-}$and $\mathrm{EAF}^{-/-} \mathrm{VHL}^{+/-}$mice, this suggests that VHL loss does not affect epithelial cell proliferation in the prostate. In the liver, the number of Ki-67-positive cells was significantly increased in $\mathrm{EAF}^{-/-} \mathrm{VHL}^{+/-}$mice compared to wild-type, EAF2 ${ }^{-1-}$ and $\mathrm{VHL}^{+/-}$mice (Fig. 4b, d). Loss of EAF2 or VHL alone did not significantly affect proliferation in the liver, suggesting that EAF2 and/or VHL may 
Table 1 Effects of VHLdeficiency on EAF2 ${ }^{+/+}$and $\mathrm{EAF} 2^{-1-}$ mice at $20-24$ mos

Phenotype $\frac{\mathrm{VHL}^{+/+}}{\mathrm{EAF} 2^{+/+} \mathrm{EAF}^{-/-}} \frac{\mathrm{VHL}^{+/-}}{\mathrm{EAF}^{+/+} \mathrm{EAF}^{-/-}}$

Liver

Vascular lesions and mild-severe angiectasis

Focal thrombus formation

Fatty change-moderate

Hepatocellular adenoma

Focal lymphocytic infiltrate

Hepatocyte loss

Hepatic fibrosis

$\begin{array}{lll} & 10 & 4 \\ 1 & & 2 \\ & 1 & 1 \\ & & 1 \\ & & 1 \\ & & 1 \\ & & 1\end{array}$

Extramedullary hematapoiesis

Chronic portal infiltrates

Number of mice examined

\section{Prostate}

Prostatic intraepithelial neoplasia

Lymphocytic interstitial infiltrates

Ductal mucus plug

Lymphoma

Stromal inflammation

Stromal edema

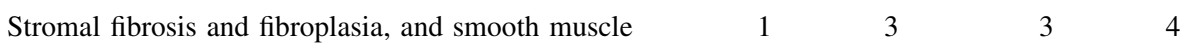
proliferation

Number of mice examined

$\begin{array}{llll}0 & 3 & 0 & 4 \\ 5 & 5 & 8 & 4 \\ & & 1\end{array}$

$\begin{array}{llll}2 & 1 & \\ 2 & 4 & 4\end{array}$

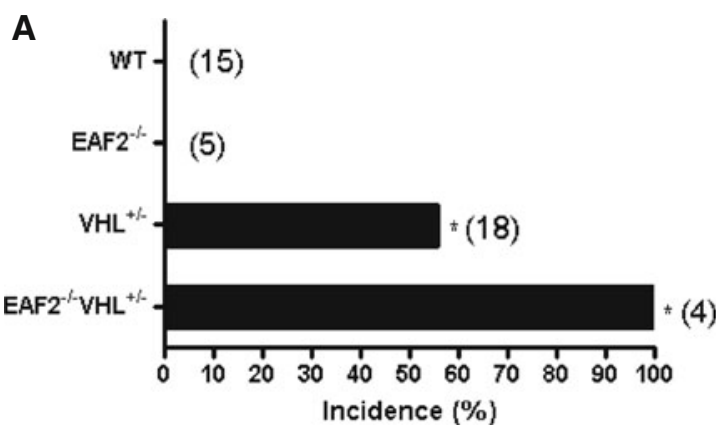

B WT

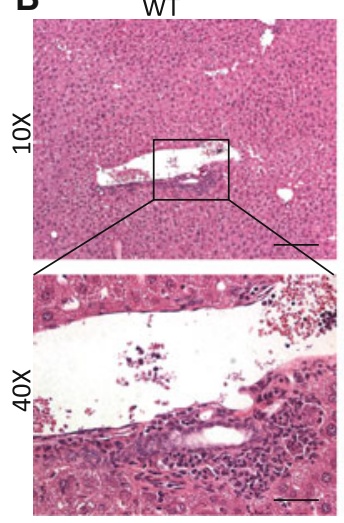

EAF2\%

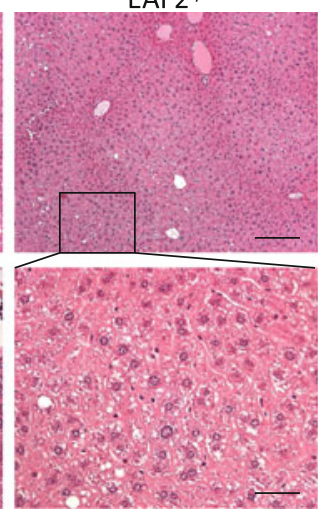

Fig. 2 Effect of combined EAF2- and VHL-deficiency on the incidence rate of hepatic vascular lesions at age 20-24 mos. $(* P<0.05)$. a Incidence rate of hepatic vascular lesions. b H\&E stain
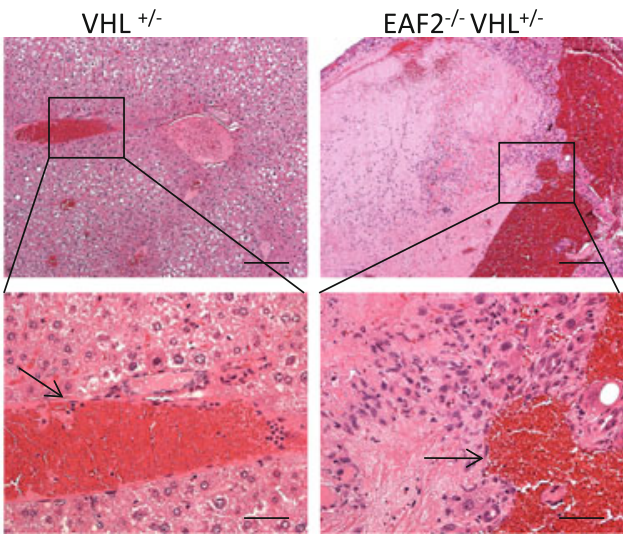

of transverse sections of liver from wild-type control (WT), EAF2 ${ }^{-/-}$, $\mathrm{VHL}^{+-}$and $\mathrm{EAF}^{-1-} \mathrm{VHL}^{+/-}$mice at age $20-24 \mathrm{mos}$. $\mathrm{VHL}^{+/-}$and $\mathrm{EAF}^{-/-} \mathrm{VHL}^{+/-}$livers displayed angiectasis (black arrows) 

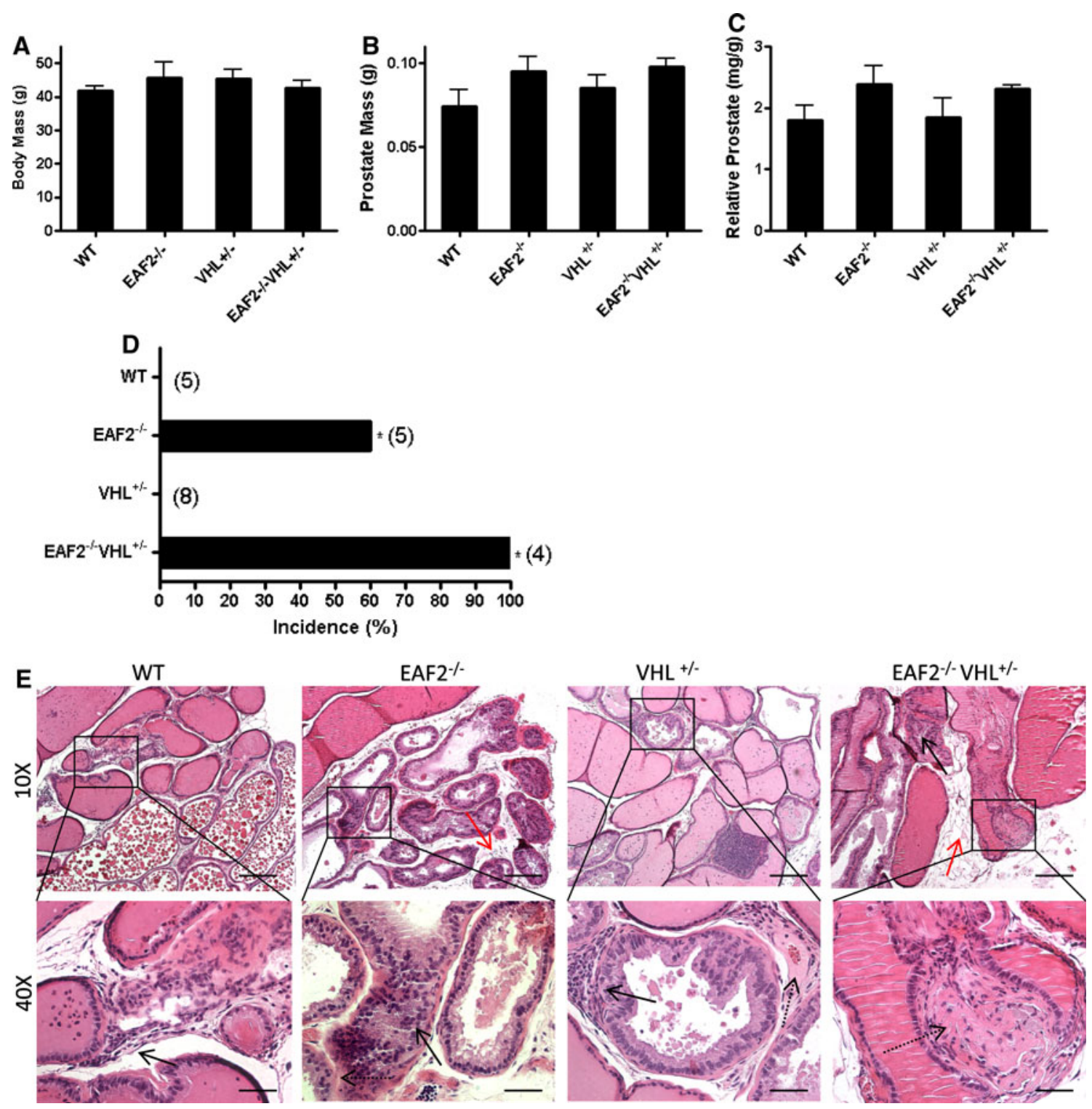

Fig. 3 Effect of combined EAF2- and VHL-deficiency on the prostate at age $20-24$ mos. a Body mass. b Absolute prostate mass. c Relative prostate mass. Data represent average of 4-8 mice per group $(P>0.05)$. d Incidence rate of prostatic intraepithelial neoplasia $(* P<0.05)$. e H\&E stain of transverse sections of prostate ventral lobes from wild-type control (WT), $\mathrm{EAF}^{-/-}, \mathrm{VHL}^{+/-}$and $\mathrm{EAF}^{-/-} \mathrm{VHL}^{+/-}$mice at age 20-24 mos. All groups displayed increased lymphocytic infiltration (black arrow, WT inset). EAF2 ${ }^{-/-}$

have tissue specific effects in regulation of cell proliferation in the prostate and the liver.

EAF2 and VHL gene deletion is associated with increased vascular density in the prostate and liver

To investigate the cooperative effects of EAF2 and VHL loss on microvessel density in the prostate and liver, we mice displayed prostatic intraepithelial neoplasia (black arrow), stromal fibrosis and fibroplasia (dashed arrow) and stromal edema (red arrow). $\mathrm{VHL}^{+/-}$mice displayed lymphocytic infiltration (black arrow), stromal fibrosis and fibroplasia (dashed arrow), but not prostatic intraepithelial neoplasia. EAF2 $2^{-/-} \mathrm{VHL}^{+/-}$mice displayed prostatic intraepithelial neoplasia (black arrow), stromal fibrosis and fibroplasia (dashed arrow) and stromal edema (red arrow)

examined the number of CD31-positive blood vessels in both tissues by immunostaining (Fig. 5). We found that the number of CD31-positive vessels per field increased significantly in the prostates of $\mathrm{EAF}^{-/-}, \mathrm{VHL}^{+-}$and $\mathrm{EAF}^{-/-} \mathrm{VHL}^{+/-}$mice as compared to wild-type control animals (Fig. 5c) and that CD31 staining increased in all lobes of the prostate (Fig. 5d). In the livers of these mice, the number of CD31-positive blood vessels increased significantly in $\mathrm{EAF}^{-/-} \mathrm{VHL}^{+/-}$mice as compared to 

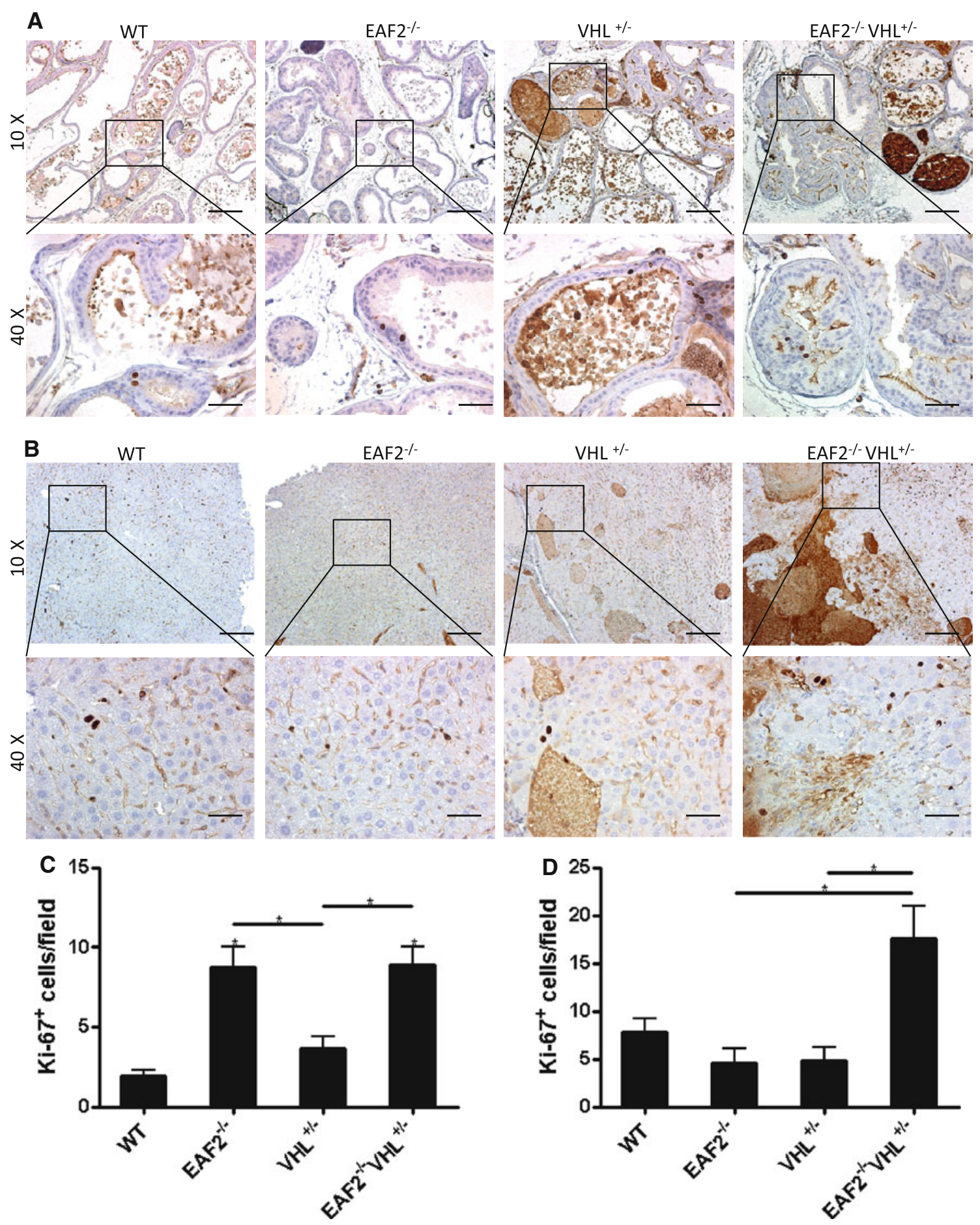

Fig. 4 Effects of EAF2- and VHL-deficiency on cellular proliferation in the prostate and liver. a $\mathrm{Ki}-67$ immunostaining in transverse sections of prostate ventral lobes from wild-type control (WT), $\mathrm{EAF}^{-1-}, \mathrm{VHL}^{+/-}$and $\mathrm{EAF} 2^{-1-} \mathrm{VHL}^{+/-}$mice at age $20-24$ mos. b Ki-67 immunostaining in transverse sections of liver from WT,

wild-type control animals. Although not statistically significant, the number of $\mathrm{CD} 31$-positive blood vessels was also increased in $\mathrm{EAF}^{-1-}$ and $\mathrm{VHL}^{+/-}$mice as compared to wild-type mice.

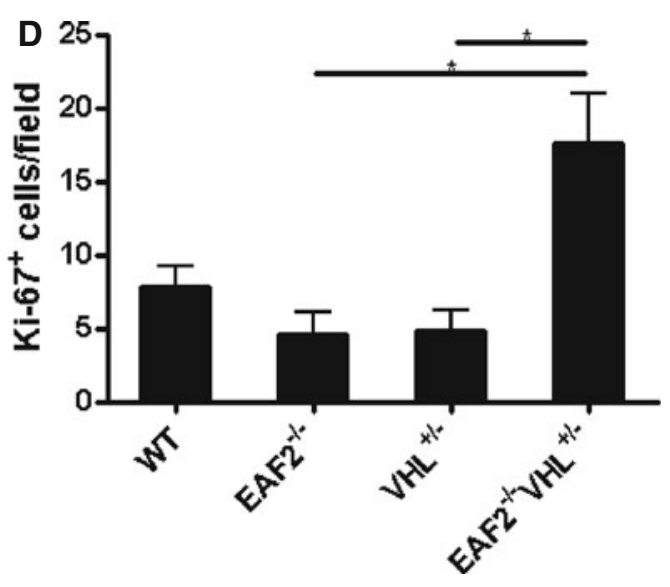

$\mathrm{EAF}^{-/-}, \mathrm{VHL}^{+/-}$and $\mathrm{EAF}^{-/-} \mathrm{VHL}^{+/-}$mice at age $20-24$ mos. Original magnification $\times 10$, inset $\times 40$. Scale bars indicate $200 \mathrm{~mm}$ in $\times 10,50 \mathrm{~mm}$ in $\times 40$. c Quantification of Ki- $67^{+}$epithelial cells in ventral prostate. d Quantification of $\mathrm{Ki}-67^{+}$cells in liver. Data represent average of $4-8$ mice per group $(* P<0.05)$

Effect of EAF2 and VHL deficiency on VHL pathway

Since HIF $1 \alpha$ is a target of VHL protein and VEGF is a HIF target, we evaluated the effects of EAF2 loss and VHL 

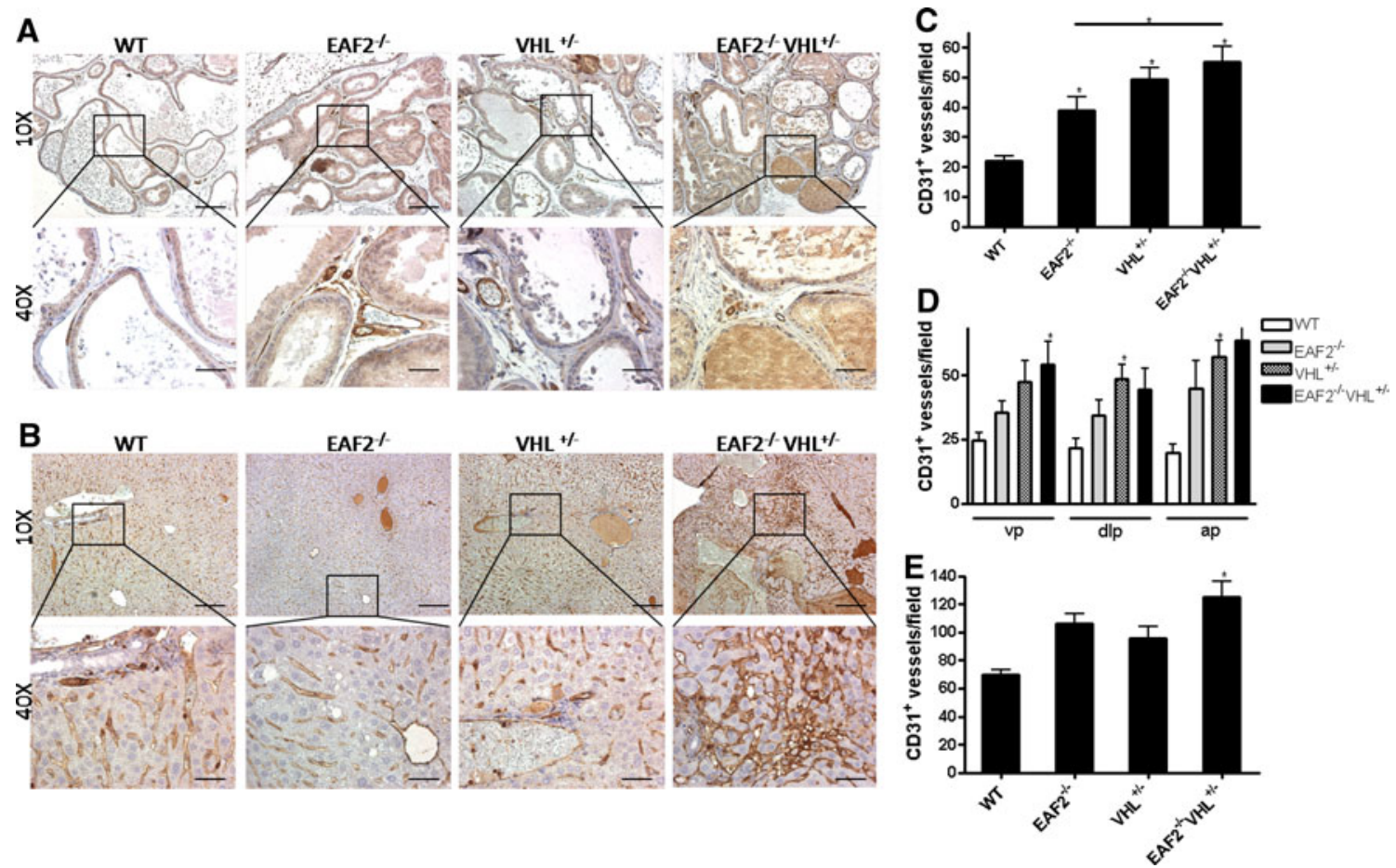

Fig. 5 Cooperative effects of EAF2- and VHL-deficiency on CD31 ${ }^{+}$ blood vessel formation in the prostate and liver. a CD31 immunostaining of vessels in transverse sections of prostate ventral lobes from wildtype control (WT), EAF2 ${ }^{-/-}, \mathrm{VHL}^{+/-}$and $\mathrm{EAF}^{-/-} \mathrm{VHL}^{+/-}$mice at age 20-24 mos. b CD31 immunostaining in transverse sections of liver from $\mathrm{WT}, \mathrm{EAF}^{-/-}, \mathrm{VHL}^{+/-}$and $\mathrm{EAF}^{-/-} \mathrm{VHL}^{+/-}$mice at age

heterozygosity on expression of these products by immunostaining. In the prostate, blood vessels stained with HIF $1 \alpha$ in all groups (Fig. 6a). Increased nuclear immunoreactivity for HIF $1 \alpha$ has previously been reported in prostate intraepithelial neoplasia in human [22] and mouse tissue [23], however no epithelial HIF1 $\alpha$ expression was found in any groups in this study. A comparison of immunostaining intensity of HIF1 $\alpha$-positive blood vessels showed an apparent additive increase in HIF $1 \alpha$ expression levels as well as the number of blood vessels in $\mathrm{EAF}^{-1-} \mathrm{VHL}^{+/-}$prostates as compared to the prostates of wild-type, $\mathrm{EAF} 2^{-/-}$and $\mathrm{VHL}^{+/-}$animals. In the livers of wild-type and $\mathrm{EAF}^{-/-}$ animals, HIF1 $\alpha$ staining was confined to blood vessels and sinusoidal lining cells and hepatocytes displayed no immunoreactivity (Fig. 6b). Increased HIF1 $\alpha$ levels in the livers of $\mathrm{EAF}^{-/-}$animals at age 12 mos were shown by western blot analysis (Fig. 6c). In $\mathrm{VHL}^{+/-}$animals, hepatocytes displayed positive cytoplasmic HIF1 $\alpha$ staining near portal areas. In $\mathrm{EAF}^{-1-} \mathrm{VHL}^{+/-}$animals there was an apparent increase in cytoplasmic and rare nuclear HIF1 $\alpha$ staining of hepatocytes amid proliferating oval cells, particularly near vascular lesions. Increased nuclear and cytoplasmic expression of HIF $1 \alpha$ in hepatocytes has been associated with a response to hypoxic lesions in murine liver [24].
20-24 mos. Original magnification $\times 10$, inset $\times 40$. Scale bars indicate $200 \mathrm{~mm}$ in $\times 10,50 \mathrm{~mm}$ in $\times 40$. c Quantification of $\mathrm{CD} 31^{+}$vessels in prostate. $\mathbf{d}$ Quantification of CD31 ${ }^{+}$vessels in the ventral (vp), dorsal-lateral (dlp) and anterior (ap) prostate. e Quantification of $\mathrm{CD} 31^{+}$vessels in the liver. Data represent average of 5-8 mice per group $(* P<0.05)$

Previously we have shown that pVHL levels are reduced in $\mathrm{EAF}^{-/-}$mice, and endogenous HIF1 $\alpha$ protein levels are increased in immortalized EAF2 ${ }^{-1-}$ MEFs under hypoxic conditions [13]. Here we show that transient transfection of GFP-EAF2 plasmids in $\mathrm{EAF}^{-1-}$ MEF cells decreased HIF1 $\alpha$ protein levels, further substantiating a role for EAF2 in potentiating the degradation of HIF1 $\alpha$ under hypoxia (Fig. 6d).

HIF1 $\alpha$ is involved in the transcriptional regulation of pro-angiogenic stimulator VEGF [25], and increased expression of VEGF has been reported in prostate cancer and benign prostatic hyperplasia [26]. In the prostate, epithelial cells, stromal cells and blood vessels were positive for VEGF immunostaining, and no apparent changes were displayed among the groups (Fig. 7a). In the liver, hepatocytes and sinusoidal lining cells were positive for VEGF immunostaining. Increased VEGF expression in the extracellular space surrounding inflammatory cells and in hepatocytes has been reported in response to hypoxia [24]. $\mathrm{EAF}^{-1-} \mathrm{VHL}^{+/-}$animals displayed areas of more intense VEGF immunostaining of hepatocytes, particularly near thrombus formations (Fig. 7b).

VHL expression has been reported in the basal epithelium of mice [27] and the basal and luminal epithelium of 

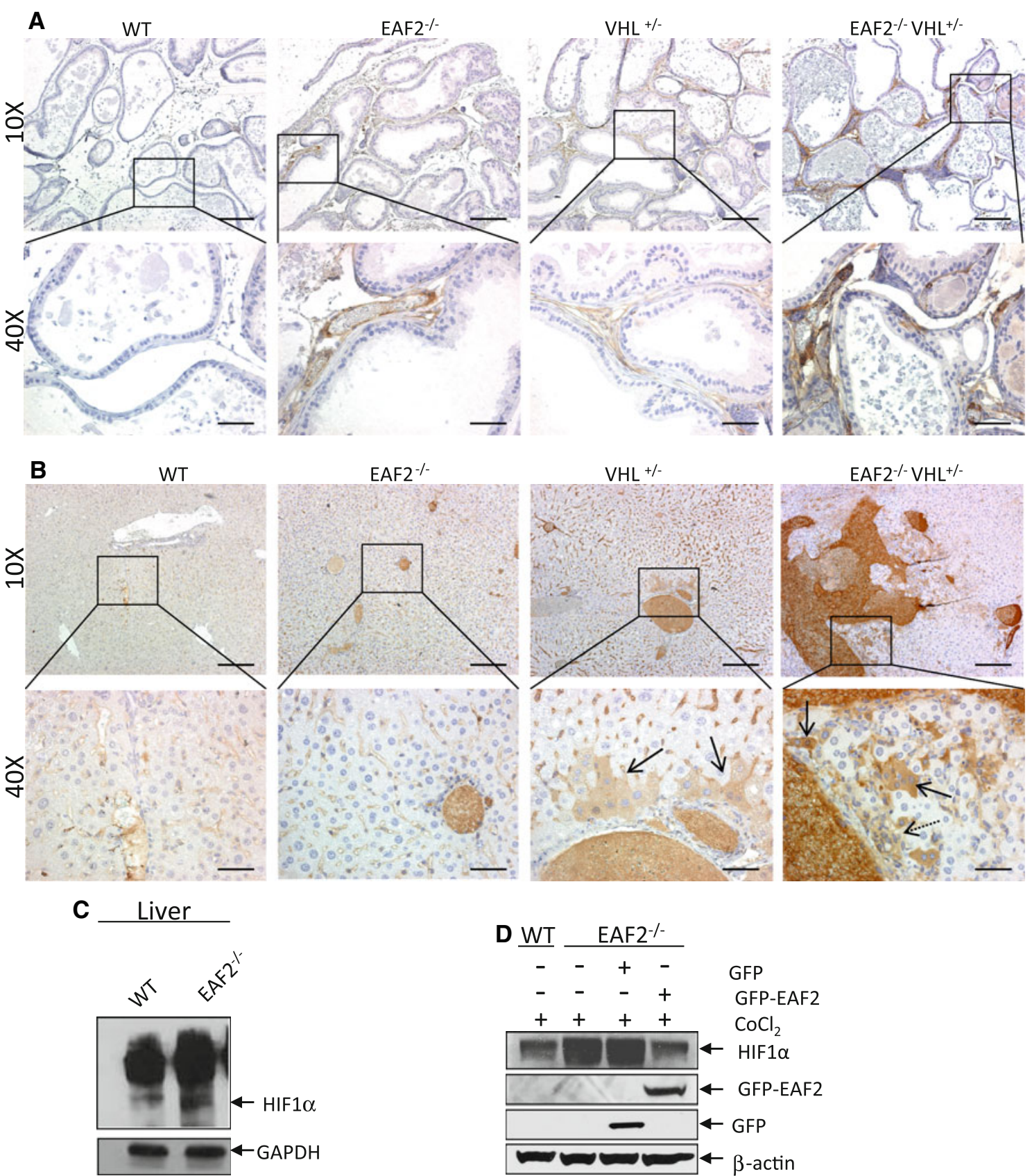

$\mathrm{EAF}^{-/-}$
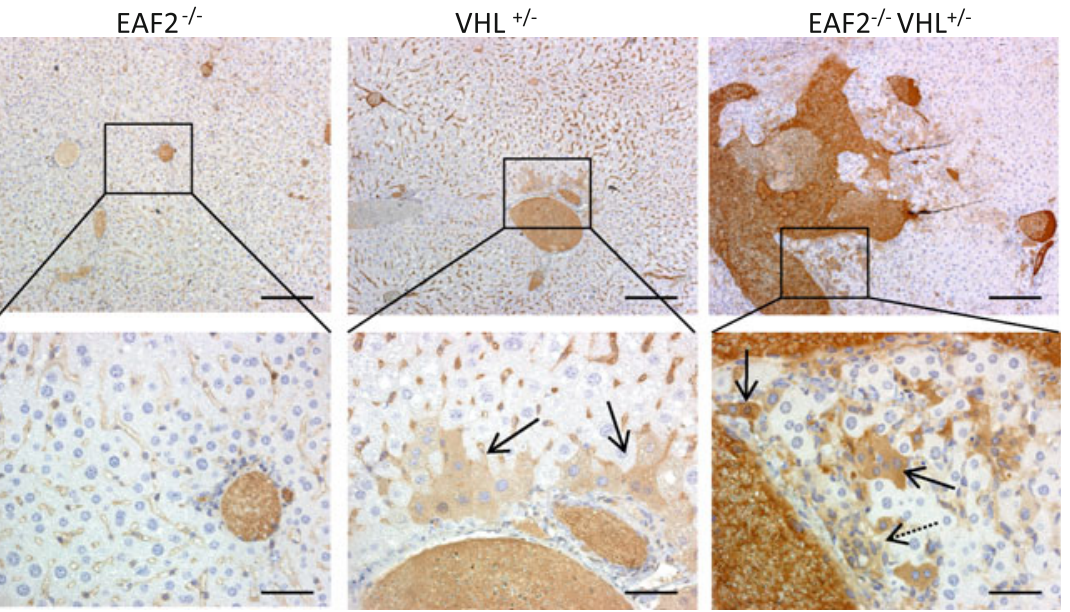

Fig. 6 Expression of HIF1 $\alpha$ in prostate and liver. a HIF $1 \alpha$ immunostaining of vessels in transverse sections of prostate ventral lobes from wild-type control (WT), EAF2 ${ }^{-1-}, \mathrm{VHL}^{+/-}$and $\mathrm{EAF}^{-1-} \mathrm{VHL}^{+/-}$ mice at age 20-24 mos. b HIF1 $\alpha$ immunostaining of vessels in transverse sections of liver from wild-type control (WT), EAF2 ${ }^{-1-}$, $\mathrm{VHL}^{+/-}$and $\mathrm{EAF}^{-/-} \mathrm{VHL}^{+/-}$mice at age $20-24 \mathrm{mos}$. $\mathrm{VHL}^{+/-}$mice displayed cytoplasmic staining of hepatocytes and sinusoidal lining cells proximal to portal areas (black arrow). $\mathrm{EAF} 2^{-1-} \mathrm{VHL}^{+/-}$mice displayed cytoplasmic staining of hepatocytes and sinusoidal lining

the human prostate [28]. In the prostates of wild-type and $\mathrm{EAF}^{-1-}$ mice, VHL immunostaining was confined to the cytoplasm of epithelial cells, and there was no apparent difference in immunostaining pattern between these two groups (Fig. 8a). In $\mathrm{VHL}^{+/-}$animals, there were random

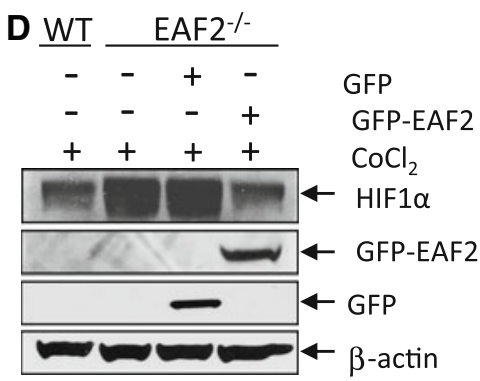

cells (black arrows) in areas of increased oval cell proliferation (dashed arrow). $\mathbf{c}$ Western blot analysis of HIF1 $\alpha$ expression in liver extracts of wild-type or EAF2 ${ }^{-1-}$ mice at age 12 mos. Blots were reprobed with GAPDH antibody to confirm equal protein loading. d Modulation of HIF $1 \alpha$ expression by EAF2 in MEF cells. EAF2 ${ }^{-/-}$MEF cells transfected with GFP-EAF2 had reduced HIF1 $\alpha$ expression. Blots were reprobed with $\beta$-actin antibody to confirm equal protein loading. Western blot images are representative of at least 3 experiments

epithelial cells that were negative for VHL immunoreactivity; and in $\mathrm{EAF}^{-1-} \mathrm{VHL}^{+-}$prostates, some areas of PIN were negative for VHL immunoreactivity. In the liver, VHL immunostaining intensity in $\mathrm{EAF}^{-1-}$ appeared to be decreased in comparison to wild-type animals, especially in 


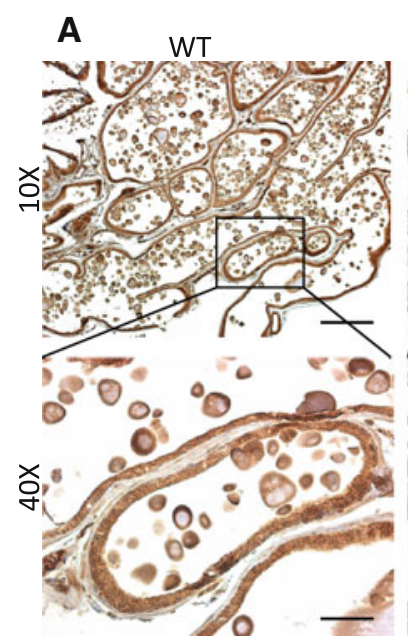

B
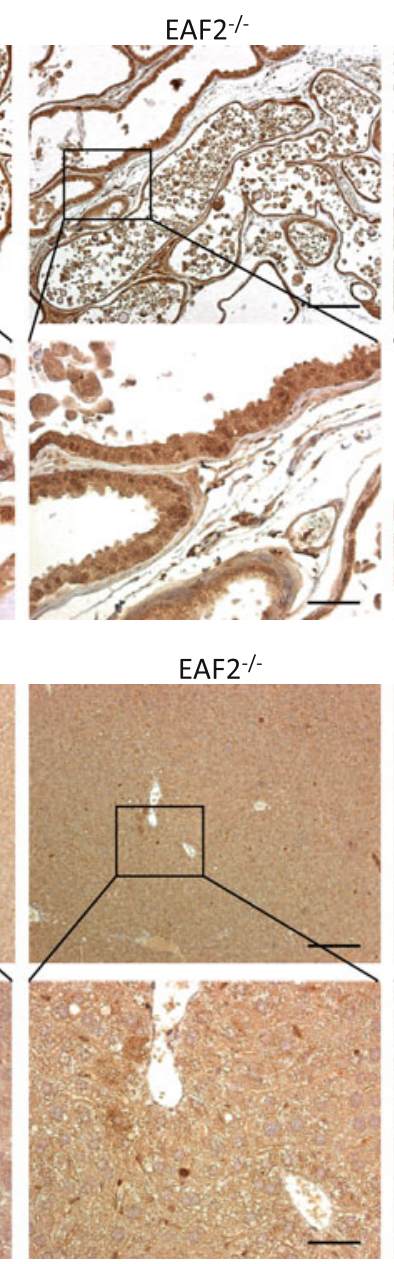

$\mathrm{EAF} \%$

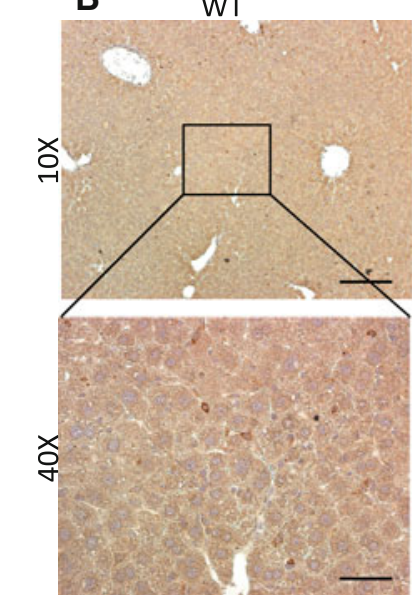

Fig. 7 Expression of VEGF in prostate and liver. a VEGF immunostaining in transverse sections of prostate ventral lobes from wildtype control (WT), $\mathrm{EAF}^{-1-} \mathrm{VHL}^{+/-}$and $\mathrm{EAF}^{-1-} \mathrm{VHL}^{+/-}$mice at age 20-24 mos. b VEGF immunostaining of in transverse sections of

areas of angiectasis (Fig. 8b). In the liver of $\mathrm{VHL}^{+/-}$ animals, areas near vascular lesions were characterized by VHL-negative proliferating oval cells and decreased VHL immunoreactivity in surrounding hepatocytes. In $\mathrm{EAF}^{-1-} \mathrm{VHL}^{+/-}$animals, hepatic vascular lesions were surrounded by VHL-negative hepatocytes and proliferating oval cells whereas areas distal to the lesions were characterized by intense cytoplasmic VHL staining in multinucleated hepatocytes.

Differential expression of EAF2 and VHL pathway genes in human prostate cancer specimens

Previously published datasets from normal and cancer cells isolated from human prostate tissue specimens were queried for differential expression of CD31, EAF2 and VHL pathway genes VHL, HIF1A, HIF1AN, VEGFA, VEGFB, and VEGFC (Fig. 9). Cell-type specific comparison of cancer versus normal luminal epithelial cells and
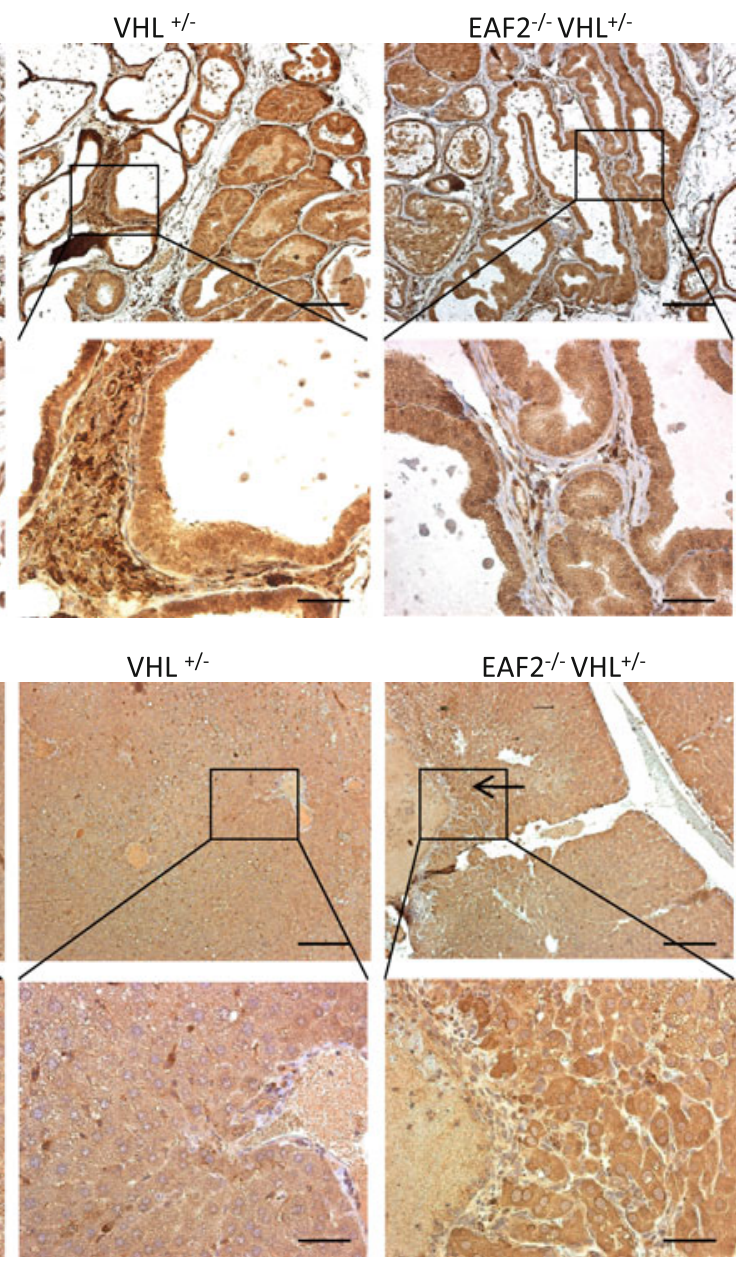

liver from wild-type control (WT), $\mathrm{EAF}^{-/-}, \mathrm{VHL}^{+/-}$and EAF $2^{-1-} \mathrm{VHL}^{+1-}$ mice at age $20-24$ mos. $\mathrm{EAF}^{-1-} \mathrm{VHL}^{+1-}$ mice displayed areas of intense cytoplasmic staining of hepatocytes (black arrow)

cancer-associated fibroblasts versus normal stromal cells showed that EAF2 was down-regulated in cancer. Additionally, CD31 and VHL pathway genes HIF1A, VEGFA and VEGFB were up-regulated in both cancer and cancerassociated fibroblasts, whereas VHL, HIF1AN and VEGFC were upregulated in cancer-associated fibroblasts but not cancer. These results from human tissue specimens correlate with the apparent increase found in the expression of HIF $1 \alpha$ and VEGF, and loss of VHL in $\mathrm{EAF}^{-/-} \mathrm{VHL}^{+/-}$ animals compared to wild-type. These data further suggest that EAF2 down-regulation may contribute to the development of an angiogenic phenotype in prostate disease.

\section{Discussion}

It has long been recognized that tumor angiogenesis is critical to tumor growth, survival and metastatic potential [29]. Microvessel density was been shown to be highly 

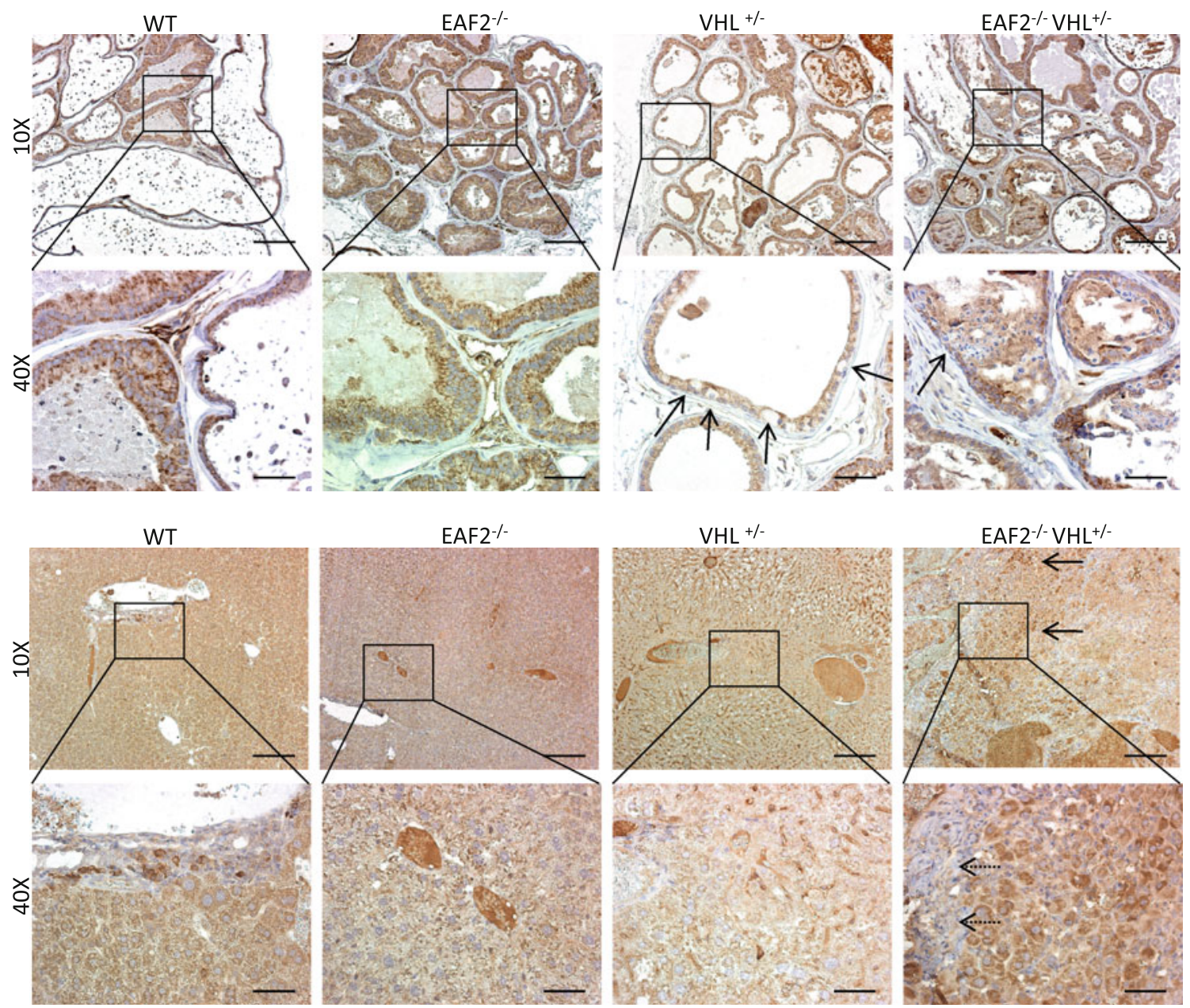

Fig. 8 Expression of VHL in prostate and liver. a VHL immunostaining in transverse sections of prostate ventral lobes from wild-type control (WT), $\mathrm{EAF}^{-/-}, \mathrm{VHL}^{+/-}$and $\mathrm{EAF}^{-/-} \mathrm{VHL}^{+/-}$mice at age 20-24 mos. VHL $^{+/-}$mice displayed sporadic negative VHL immunoreactivity (black arrows), and $\mathrm{EAF}^{-/-} \mathrm{VHL}^{+/-}$mice displayed negative VHL immunoreactivity in PIN lesions (black arrow). b VHL immunostaining of in transverse sections of liver from wild-type control (WT), $\mathrm{EAF}^{-/-}, \mathrm{VHL}^{+/-}$and $\mathrm{EAF}^{-/-} \mathrm{VHL}^{+/-}$mice at age

correlated with disease progression in both prostate [30] and hepatocellular carcinoma [31]. Loss of tumor suppressors VHL and EAF2 have individually been shown to induce pro-angiogenic phenotypes in murine models. $\mathrm{VHL}^{+/-}$mice developed hepatic vascular lesions [7] and $\mathrm{EAF}^{-1-}$ mice developed PIN lesions [15]. Furthermore, EAF2 has been shown to bind and stabilize pVHL, thereby inhibiting HIF-driven angiogenesis; and $\mathrm{EAF}^{-1-}$ mice have reduced levels of pVHL in several major organs [13]. In the current study, combined deficiency of EAF2 and VHL led to a highly penetrant pro-angiogenic phenotype in the murine liver and prostate.

VHL deficiency consistently increased the incidence of hepatic vascular lesions across three mouse strains at ages $>12$ mos, and there seemed to be no significant

20-24 mos. Proliferating oval cells near areas of angiectasis in $\mathrm{VHL}^{+/-}$animals were negative (black arrow) and surrounding hepatocytes had reduced VHL immunoreactivity. EAF2 ${ }^{-1-} \mathrm{VHL}^{+/-}$ mice displayed areas of intense cytoplasmic staining of hepatocytes (black arrows) and negative VHL immunoreactivity in proliferating oval cells and hepatocytes (inset, dashed arrow) near areas of angiectasis

discrepancies in the hepatic phenotype among different strains (Fig. 1). EAF2 deficiency increased the angiogenic effects of VHL heterozygosity in the murine liver. While not statistically significant $(P=0.08), \mathrm{EAF}^{-/-} \mathrm{VHL}^{+/-}$ animals had a marked increase in the incidence of hepatic vascular lesions compared to $\mathrm{VHL}^{+/-}$animals $(100 \%$ vs. $55.6 \%$ ) (Fig. 2). No lesions occurred in $\mathrm{EAF} 2^{-1-}$ or wildtype mice. VHL or EAF2 deficiency alone had no effect on cellular proliferation in the liver (Fig. 4). Hepatic lesions in $\mathrm{EAF} 2^{-1-} \mathrm{VHL}^{+/-}$mice displayed a statistically significant increase in proliferation compared to livers of $\mathrm{EAF}^{-1-}$, $\mathrm{VHL}^{+/-}$and wild-type mice as measured by Ki-67 positive cells. The combined effects of EAF2 and VHL loss on proliferation were not seen in the prostate, however. Liver blood vessel formation determined by CD31 immunostaining was 


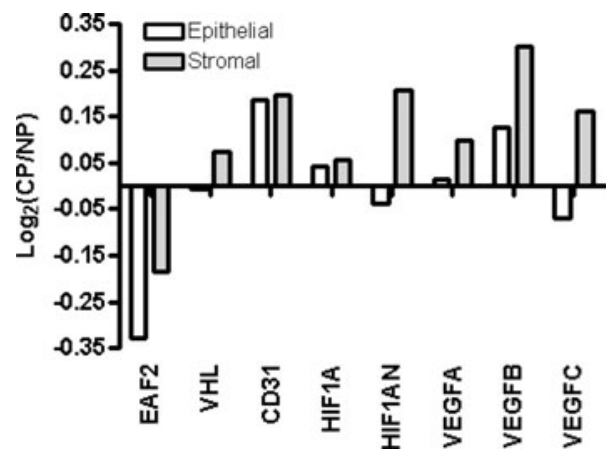

Fig. 9 Expression profile of EAF2 and VHL pathway genes in prostate cancer and cancer-associated fibroblasts compared to normal prostate epithelial and stromal cells as determined by analysis of sorted $\mathrm{CD}^{2} 6^{+}$(cancer and normal epithelial) cells, CD90 ${ }^{+}$(cancerassociated fibroblast) cells and $\mathrm{CD}_{49} \mathrm{a}^{+}$(normal stromal) from human tissue specimens. Positive $\log 2$ (Cancer/Normal) on the $y$-axis indicates increased cancer expression while negative $\log 2$ indicates decreased cancer expression

also significantly increased in $\mathrm{EAF} 2^{-1-} \mathrm{VHL}^{+/-}$compared to the wild-type liver (Fig. 5). To a lesser degree, the livers of $\mathrm{EAF}^{-/-}$and $\mathrm{VHL}^{+/-}$alone mice also displayed increased microvessel density which was consistent with previous reports $[10,14]$.

EAF2 deficiency has previously been shown to induce PIN in mice [15] and down-regulation of EAF2 expression has been reported in prostate cancer [15, 18]. VHL heterozygosity increased the incidence of PIN lesions in $\mathrm{EAF}^{-1-}$ mice, from $60 \%$ in $\mathrm{EAF}^{-1-}$ mice to $100 \%$ in $\mathrm{EAF}^{-1-} \mathrm{VHL}^{+/-}$mice (Fig. 3). PIN lesions in $\mathrm{EAF}^{-1-} \mathrm{VHL}^{+/-}$mice were accompanied by stromal inflammation, fibrosis and fibroplasia and smooth muscle proliferation and a statistically significant increase in microvessel density when compared to $\mathrm{EAF}^{-1-}, \mathrm{VHL}^{+/-}$ and wild-type mice.

Decreased pVHL expression has been reported in the affected tissues of VHL-deficient mice [8, 32, 33], due at least in part to the absence of one VHL allele. Rankin et al. [11] showed that renal tubule cysts, but not normal renal cortical cells exhibited biallelic VHL gene inactivation in VHL-conditionally deficient mice. We found lost or reduced $\mathrm{pVHL}$ expression in $\mathrm{EAF} 2^{-/-} \mathrm{VHL}^{+/-}$in areas of PIN in the prostate and in angiectasis of the liver, suggesting that VHL inactivation was associated with the development of these lesions as well (Fig. 8). Loss or reduced pVHL expression could be the result of allelic loss. However, it could also occur through transcriptional or post-transcriptional mechanisms. It was not clear from our analyses whether pVHL loss was associated with a higher grade of PIN in $\mathrm{EAF}^{-/-} \mathrm{VHL}^{+/-}$mice as compared to PIN seen in $\mathrm{EAF}^{-/-}$mice. Although VHL expression in the prostate epithelium has been reported previously
$[27,28]$, the physiological role of the VHL gene in prostatic tissue remains to be elucidated.

Here we demonstrate that combined deficiency of VHL and EAF2 in mice increases angiogenesis in murine prostate and liver. Furthermore, this angiogenic phenotype was consistent with an increased incidence of pVHL-negative PIN and hepatic vascular lesions. The EAF2 ${ }^{-1-} \mathrm{VHL}^{+/-}$ mouse model demonstrates that these two tumor suppressors cooperate in the regulation of angiogenesis and that loss of these genes contributes to the development of neoplasia in the liver and prostate.

Acknowledgments We are grateful to Ricardo Vencio and Julio Garcia for gene array data analyses and to Jianhua Xu, Aiyuan Zhang, Katie Leschak, Dawn Everard, Marie Acquafondata and Marianne Notaro for technical support. We also thank Dr. Laura Schmidt from NCI for providing $\mathrm{VHL}^{+/-}$mice. This work was funded in part by grants T32 DK007774, R37 DK51193, R01CA120386, CA78335 and CA125930 (JG).

Conflict of interest The authors indicate no potential conflicts of interest.

Open Access This article is distributed under the terms of the Creative Commons Attribution Noncommercial License which permits any noncommercial use, distribution, and reproduction in any medium, provided the original author(s) and source are credited.

\section{References}

1. Maxwell PH, Wiesener MS, Chang GW, Clifford SC, Vaux EC, Cockman ME, Wykoff CC, Pugh CW, Maher ER, Ratcliffe PJ (1999) The tumour suppressor protein VHL targets hypoxiainducible factors for oxygen-dependent proteolysis. Nature 399:271-275

2. Ohh M, Park CW, Ivan M, Hoffman MA, Kim TY, Huang LE, Pavletich N, Chau V, Kaelin WG (2000) Ubiquitination of hypoxia-inducible factor requires direct binding to the betadomain of the von Hippel-Lindau protein. Nat Cell Biol 2:423-427

3. Rathmell WK, Simon MC (2005) VHL: oxygen sensing and vasculogenesis. J Thromb Haemost 3:2627-2632

4. Liu W, Xin H, Eckert DT, Brown JA, Gnarra JR (2010) Hypoxia and cell cycle regulation of the von Hippel-Lindau tumor suppressor. Oncogene 30:21-31

5. Hu CJ, Wang LY, Chodosh LA, Keith B, Simon MC (2003) Differential roles of hypoxia-inducible factor 1alpha (HIF1alpha) and HIF-2alpha in hypoxic gene regulation. Mol Cell Biol 23:9361-9374

6. Gnarra JR, Ward JM, Porter FD, Wagner JR, Devor DE, Grinberg A, Emmert-Buck MR, Westphal H, Klausner RD, Linehan WM (1997) Defective placental vasculogenesis causes embryonic lethality in VHL-deficient mice. Proc Natl Acad Sci USA 94:9102-9107

7. Haase VH, Glickman JN, Socolovsky M, Jaenisch R (2001) Vascular tumors in livers with targeted inactivation of the von Hippel-Lindau tumor suppressor. Proc Natl Acad Sci USA 98:1583-1588 
8. Ma W, Tessarollo L, Hong SB, Baba M, Southon E, Back TC, Spence S, Lobe CG, Sharma N, Maher GW et al (2003) Hepatic vascular tumors, angiectasis in multiple organs, and impaired spermatogenesis in mice with conditional inactivation of the VHL gene. Cancer Res 63:5320-5328

9. Kleymenova E, Everitt JI, Pluta L, Portis M, Gnarra JR, Walker CL (2004) Susceptibility to vascular neoplasms but no increased susceptibility to renal carcinogenesis in Vhl knockout mice. Carcinogenesis 25:309-315

10. Chen S, Sanford CA, Sun J, Choi V, Van Dyke T, Samulski RJ, Rathmell WK (2010) VHL and PTEN loss coordinate to promote mouse liver vascular lesions. Angiogenesis 13:59-69

11. Rankin EB, Tomaszewski JE, Haase VH (2006) Renal cyst development in mice with conditional inactivation of the von Hippel-Lindau tumor suppressor. Cancer Res 66:2576-2583

12. Shen HC, Adem A, Ylaya K, Wilson A, He M, Lorang D, Hewitt SM, Pechhold K, Harlan DM, Lubensky IA et al (2009) Deciphering von Hippel-Lindau (VHL/Vhl)-associated pancreatic manifestations by inactivating $\mathrm{Vhl}$ in specific pancreatic cell populations. PLoS One 4:e4897

13. Xiao W, Ai J, Habermacher G, Volpert O, Yang X, Zhang AY, Hahn J, Cai X, Wang Z (2009) U19/Eaf2 binds to and stabilizes von hippel-lindau protein. Cancer Res 69:2599-2606

14. Su F, Pascal LE, Xiao W, Wang Z (2009) Tumor suppressor U19/ EAF2 regulates thrombospondin-1 expression via p53. Oncogene 29:421-431

15. Xiao W, Zhang Q, Habermacher G, Yang X, Zhang AY, Cai X, Hahn J, Liu J, Pins M, Doglio L et al (2008) U19/Eaf2 knockout causes lung adenocarcinoma, B-cell lymphoma, hepatocellular carcinoma and prostatic intraepithelial neoplasia. Oncogene 27:1536-1544

16. Lindstedt L, Schaeffer PJ (2002) Use of allometry in predicting anatomical and physiological parameters of mammals. Lab Anim 36:1-19

17. Oudes AJ, Campbell DS, Sorensen CM, Walashek LS, True LD, Liu AY (2006) Transcriptomes of human prostate cells. BMC Genom 7:92

18. Pascal LE, Vencio RZ, Page LS, Liebeskind ES, Shadle CP, Troisch P, Marzolf B, True LD, Hood LE, Liu AY (2009) Gene expression relationship between prostate cancer cells of Gleason 3, 4 and normal epithelial cells as revealed by cell type-specific transcriptomes. BMC Cancer 9:452

19. Pascal LE, Goo YA, Vencio RZ, Page LS, Chambers AA, Liebeskind ES, Takayama TK, True LD, Liu AY (2009) Gene expression down-regulation in $\mathrm{CD} 90+$ prostate tumor-associated stromal cells involves potential organ-specific genes. BMC Cancer 9:317

20. Irizarry RA, Hobbs B, Collin F, Beazer-Barclay YD, Antonellis KJ, Scherf U, Speed TP (2003) Exploration, normalization, and summaries of high density oligonucleotide array probe level data. Biostatistics 4:249-264

21. Marzolf B, Deutsch EW, Moss P, Campbell D, Johnson MH, Galitski T (2006) SBEAMS-microarray: database software supporting genomic expression analyses for systems biology. BMC Bioinform 7:286

22. Zhong H, Semenza GL, Simons JW, De Marzo AM (2004) Upregulation of hypoxia-inducible factor 1alpha is an early event in prostate carcinogenesis. Cancer Detect Prev 28:88-93

23. Huss WJ, Hanrahan CF, Barrios RJ, Simons JW, Greenberg NM (2001) Angiogenesis and prostate cancer: identification of a molecular progression switch. Cancer Res 61:2736-2743

24. Araujo AP, Frezza TF, Allegretti SM, Giorgio S (2010) Hypoxia, hypoxia-inducible factor-1alpha and vascular endothelial growth factor in a murine model of Schistosoma mansoni infection. Exp Mol Pathol 89:327-333

25. Carmeliet P, Dor Y, Herbert JM, Fukumura D, Brusselmans K, Dewerchin M, Neeman M, Bono F, Abramovitch R, Maxwell P et al (1998) Role of HIF-1alpha in hypoxia-mediated apoptosis, cell proliferation and tumour angiogenesis. Nature 394:485-490

26. Lekas A, Lazaris AC, Deliveliotis C, Chrisofos M, Zoubouli C, Lapas D, Papathomas T, Fokitis I, Nakopoulou L (2006) The expression of hypoxia-inducible factor-1alpha (HIF-1alpha) and angiogenesis markers in hyperplastic and malignant prostate tissue. Anticancer Res 26:2989-2993

27. Nagashima Y, Miyagi Y, Udagawa K, Taki A, Misugi K, Sakai N, Kondo K, Kaneko S, Yao M, Shuin T (1996) Von HippelLindau tumour suppressor gene. Localization of expression by in situ hybridization. J Pathol 180:271-274

28. Corless CL, Kibel AS, Iliopoulos O, Kaelin WG Jr (1997) Immunostaining of the von Hippel-Lindau gene product in normal and neoplastic human tissues. Hum Pathol 28:459-464

29. Folkman J (1971) Tumor angiogenesis: therapeutic implications. N Engl J Med 285:1182-1186

30. Weidner N, Carroll PR, Flax J, Blumenfeld W, Folkman J (1993) Tumor angiogenesis correlates with metastasis in invasive prostate carcinoma. Am J Pathol 143:401-409

31. Tanigawa N, Lu C, Mitsui T, Miura S (1997) Quantitation of sinusoid-like vessels in hepatocellular carcinoma: its clinical and prognostic significance. Hepatology 26:1216-1223

32. Iguchi M, Kakinuma Y, Kurabayashi A, Sato T, Shuin T, Hong SB, Schmidt LS, Furihata M (2008) Acute inactivation of the VHL gene contributes to protective effects of ischemic preconditioning in the mouse kidney. Nephron Exp Nephrol 110:e82e90

33. Zanesi N, Mancini R, Sevignani C, Vecchione A, Kaou M, Valtieri M, Calin GA, Pekarsky Y, Gnarra JR, Croce CM (2005) et al: Lung cancer susceptibility in Fhit-deficient mice is increased by Vhl haploinsufficiency. Cancer Res 65:6576-6582 